\title{
MATLAB Tools for Improved Characterization and Quantification of Volcanic Incandescence in Webcam Imagery: Applications at Kīlauea Volcano, Hawai'i
}

By Matthew R. Patrick, James P. Kauahikaua, and Loren Antolik

Chapter 1 of

Section A, Methods Used in Volcano Monitoring of Book 13, Volcano

Monitoring

Techniques and Methods 13-A1

U.S. Department of the Interior

U.S. Geological Survey 


\section{U.S. Department of the Interior \\ KEN SALAZAR, Secretary}

\section{U.S. Geological Survey \\ Marcia K. McNutt, Director}

\section{U.S. Geological Survey, Reston, Virginia: 2010}

For additional information write to:

U.S. Geological Survey

Box 25046, Mail Stop 421, Denver Federal Center

Denver, C0 80225-0046

This report and any updates to it are available online at: http://pubs.usgs.gov/tm/tm13a1/

For more information about the USGS and its products:

Telephone: 1-888-ASK-USGS

World Wide Web: http://www.usgs.gov/

Any use of trade, product, or firm names in this publication is for descriptive purposes only and does not imply endorsement by the U.S. Government.

Although this report is in the public domain, it may contain copyrighted materials that are noted in the text. Permission to reproduce those items must be secured from the individual copyright owners.

Suggested citation

Patrick, M.R., Kauahikaua, J.P., and Antolik, L., 2010, MATLAB tools for improved characterization and quantification of volcanic incandescence in Webcam imagery; applications at Kīlauea Volcano, Hawai'i: U.S. Geological Survey Techniques and Methods 13-A1, $16 \mathrm{p}$. 


\section{Contents}

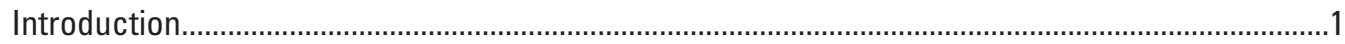

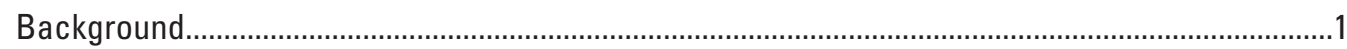

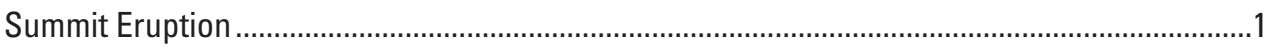

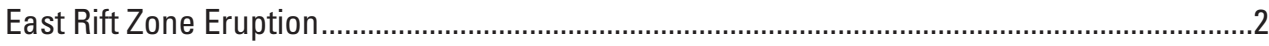

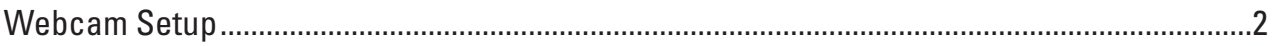

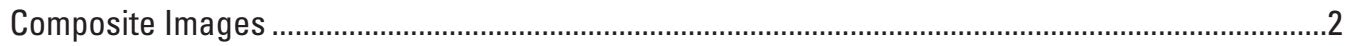

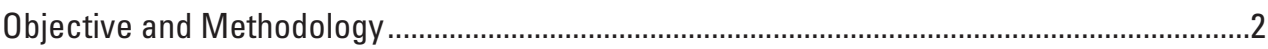

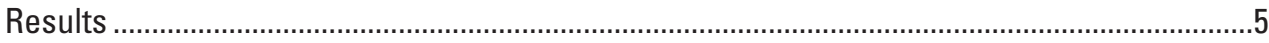

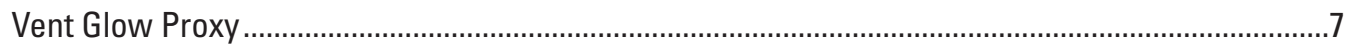

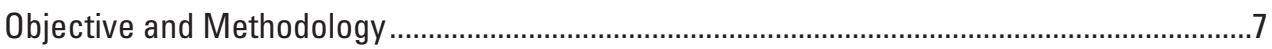

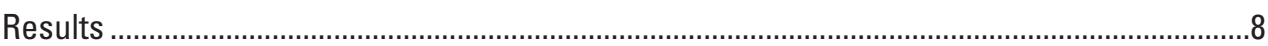

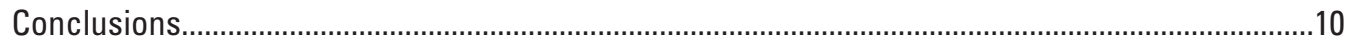

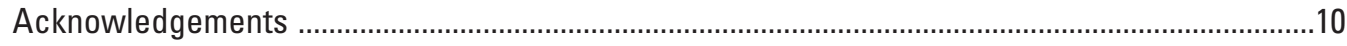

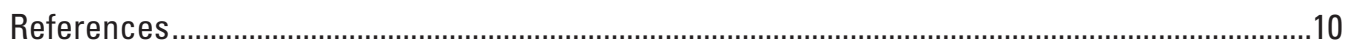

Appendix 1. MATLAB Code for Composite Image Generation.........................................................12

Appendix 2. MATLAB Code for Vent Glow Measurement .............................................................14

\section{Figures}

1. Maps and images of areas monitored by Webcams on Kỉlauea..................................................3

2. Cartoon showing the principle of composite image generation.....................................................5

3. Selected composite images of glow at the Halema'uma'u vent, with graph

of daily vent glow values shown below from March 2008 to July 2009 ...............................6

4. Composite images from July 7, 2008, showing several breakouts from the TEB lava tube ..........8

5. Comparison of vent glow values with other monitoring datasets ............................................... 
This page left intentionally blank. 


\title{
MATLAB Tools for Improved Characterization and Quantification of Volcanic Incandescence in Web- cam Imagery: Applications at Kīlauea Volcano, Hawai'i
}

\author{
By Matthew R. Patrick, James P. Kauahikaua, and Loren Antolik
}

\section{Introduction}

Webcams are now standard tools for volcano monitoring and are used at observatories in Alaska (Snedigar and others, 2006), the Cascades (Poland and others, 2008a), Kamchatka (Kirianov and others, 2002), Hawai ' $\mathrm{i}$ (Hoblitt and others, 2008), Italy (Behncke and others, 2009), and Japan (Tupper and others, 2003), among other locations. Webcam images allow invaluable documentation of activity and provide a powerful comparative tool for interpreting other monitoring datastreams, such as seismicity (DeRoin and others, 2005; De Angelis and McNutt, 2007) and deformation (Poland and others, 2008b). Automated image processing can improve the time efficiency and rigor of Webcam image interpretation, and potentially extract more information on eruptive activity. For instance, Lovick and others (2008) provided a suite of processing tools that performed such tasks as noise reduction, eliminating uninteresting images from an image collection, and detecting incandescence, with an application to dome activity at Mount St. Helens during 2007.

In this paper, we present two very simple automated approaches for improved characterization and quantification of volcanic incandescence in Webcam images at Kìlauea Volcano, Hawai' $i$. The techniques are implemented in MATLAB (version 2009b, ® The Mathworks, Inc.) to take advantage of the ease of matrix operations. Incandescence is a useful indictor of the location and extent of active lava flows and also a potentially powerful proxy for activity levels at open vents. We apply our techniques to a period covering both summit and east rift zone activity at Kīlauea during 2008-2009 and compare the results to complementary datasets (seismicity, tilt) to demonstrate their integrative potential. A great strength of this study is the demonstrated success of these tools in an operational setting at the Hawaiian Volcano Observatory (HVO) over the course of more than a year. Although applied only to Webcam images here, the techniques could be applied to any type of sequential images, such as time-lapse photography.
We expect that these tools are applicable to many other volcano monitoring scenarios, and the two MATLAB scripts, as they are implemented at HVO, are included in the appendixes. These scripts would require minor to moderate modifications for use elsewhere, primarily to customize directory navigation. If the user has some familiarity with MATLAB, or programming in general, these modifications should be easy. Although we originally anticipated needing the Image Processing Toolbox, the scripts in the appendixes do not require it. Thus, only the base installation of MATLAB is needed. Because fairly basic MATLAB functions are used, we expect that the script can be run successfully by versions earlier than $2009 \mathrm{~b}$.

\section{Background}

\section{Summit Eruption}

Following approximately 3 months of increasing sulfur dioxide $\left(\mathrm{SO}_{2}\right)$ emissions and seismic tremor at the summit of Kîlauea Volcano, a small explosive eruption on March 19, 2008, accompanied the opening of a 35-m-wide vent on the southeast wall of Halema 'uma 'u Crater (Wilson and others, 2008). The new vent has been the source of a persistent $\sim 1$-km-high gas plume (fig. 1) carrying minor amounts of tephra (Swanson and others, 2009), and the vent has widened to $130 \mathrm{~m}$, as of this writing. Seven additional small explosive eruptions have deposited coarse ejecta within a few hundred meters of the vent, covering the area of the former Halema 'uma'u Overlook (Orr and others, 2008). Glow from the vent has been common but discontinuous, and it has been observed to fluctuate in concert with other monitoring datastreams. For instance, episodic tremor bursts-normally lasting a few minutes each-have produced glow fluctuations on an equivalent time scale. Also, glow brightness has been 
observed to change along with short-term (several days) variations in summit deflation and inflation.

One day before the March 19, 2008, vent opening, a Canon VB-C50i Webcam was installed in the HVO tower, which provides a clear view of the new vent in Halema'uma ' $u$ Crater at a distance of $1.9 \mathrm{~km}$. This Webcam (named "KIcam") is a pan-tilt-zoom IP model, with an image size of $640 \times 480$ pixels, described by Hoblitt and others (2008). Image acquisition is performed every 2 minutes, with the camera capturing a three-scene panorama of Halema 'uma' $u$ Crater, a zoomed-in image ( $200 \mathrm{~m}$ field of view) of the new vent, and two wide-angle views of the vent and the plume.

In August and September 2009, two additional Webcams were installed to monitor the summit activity, for a total of three summit Webcams. Both additions are Stardot Netcam SC 5-megapixel IP cameras, which are low-light sensitive (due to a mechanical infrared filter), with a fixed field of view (that is, not pan-tilt-zoom). One of these cameras is situated in the HVO tower and named "K2cam." The other ("HMcam") is located at the Halema 'uma 'u Overlook and is pointed directly into the vent. Both of these cameras acquire images at long intervals (every 15 minutes) during the day and short intervals (every 2 minutes) at night, when their low-light capability is especially valuable.

\section{East Rift Zone Eruption}

Kîlauea's current east rift zone eruption began on January 3, 1983. Before July 2007, the eruption discharged lava primarily from vents at $\mathrm{Pu}{ }^{\prime} \mathrm{u}$ ' $\mathrm{O}^{`} \overline{\mathrm{o}}$ cone and Kupaianaha shield (Heliker and Mattox, 2003). On July 21, 2007, four en-echelon fissures opened between these two edifices (fig. 1; Poland and others 2008b), and perched lava ponds began to grow rapidly over the dominant vents. Pond-wall collapses produced several short-lived, high-volume flows before activity focused on the easternmost fissure (fissure D; fig. 1). Effusion from fissure D between July and December resulted in a 1.4-km-long, northeast-trending channel, perched as much as $45 \mathrm{~m}$ above the pre-July surface. On November 21, 2007, the day before the U.S. Thanksgiving holiday, a breakout near the vent diverted flows toward the south. The "Thanksgiving Eve Breakout" (TEB) flow traveled southward through the abandoned Royal Gardens subdivision and reached the ocean on March 5, 2008. The flow has persisted to this day and has been largely confined to a lava tube system since March 2008, but sporadic breakouts from the tube system have been a hazard concern.

Two Webcams (both Canon VB-C50i models) have been installed to monitor the ongoing east rift zone activity. The first, named "POcam," was installed on the rim of $\mathrm{Pu}$ 'u 'Ō‘o crater on February 13, 2004 (Hoblitt and others, 2008). This camera currently acquires a four-frame panorama of the crater every 5 minutes. $\mathrm{Pu}{ }^{\prime} \mathrm{u}$ ' $\overline{\mathrm{O}}^{`} \overline{\mathrm{o}}$ is located over the east rift zone magma reservoir, which supplies the current TEB flow field, and is, thus, a site for potential changes in activity. The second ("TEcam") was installed on the upper east flank of $\mathrm{Pu}^{\prime} \mathrm{u}$ ' $\mathrm{O}^{`} \mathrm{o}$ cone on January 25, 2008, providing a perched view of TEB flow field activity $2.5 \mathrm{~km}$ to the east. This camera acquires a six-frame panorama of the proximal flow field every 5 minutes. This portion of the flow field is a common location for breakouts, which can travel several kilometers downslope from the lava tube. The distal flow field, which includes the Royal Gardens subdivision, coastal plain, and ocean entry area, is currently not monitored by Webcams because of telemetry limitations.

\section{Webcam Setup}

In summary, there are currently three Webcams monitoring Kîlauea's summit (KIcam, K2cam, and HMcam) and two monitoring the east rift zone (POcam and TEcam). The pan-tilt-zoom Webcams (KIcam, POcam, and TEcam) are programmed to take a sequence of different images, each with a specific zoom factor and viewing orientation (azimuth and inclination), at specified intervals (generally several minutes). We refer to these individual views as "frames." The TEB Webcam (TEcam), for instance, is programmed to take a panorama across the flow field every 5 minutes, consisting of frames L (left), M (middle), R (right), R1, R2, and R3. The fixed-field-of-view Webcams (K2cam and HMcam), which do not take panoramas, acquire only a single frame (M).

\section{Composite Images}

\section{Objective and Methodology}

Webcam images at HVO are collected at intervals of 2-15 minutes. Over the course of each night there may be as many as several hundred images - for each Webcam frameto review for activity. This review has consumed a significant amount of time each morning to produce the daily Kîlauea update: http://volcanoes.usgs.gov/hvo/activity/kilaueastatus. php. To make the review of the previous night's activity more efficient, we wanted to produce a single image that showed all of the incandescence in a given frame throughout the entire night.

Originally, we thought that a summation (stacking) of nightly images could produce a suitable summary of incandescence, but tests of this approach showed that brief or subtle episodes of incandescence were substantially muted by the effective averaging that the summation produces.

A superior approach involved scanning all of the images for a given night and recording the maximum brightness value - among all the images - at each pixel location. These maximum values were used to construct what we call a "composite" image. Figure 2 gives a simplistic graphical depiction of how the composite images are made. 


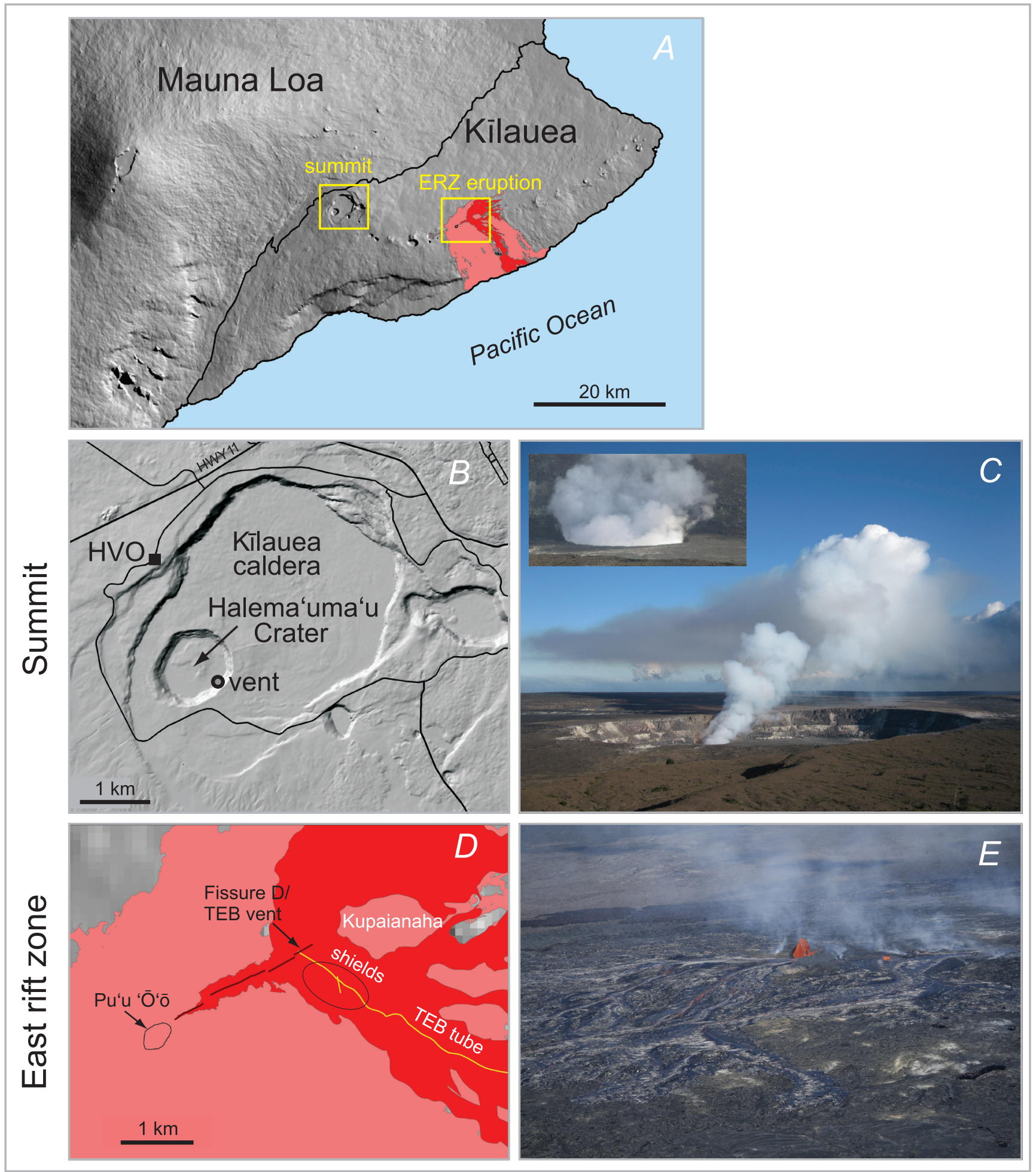

Figure 1. Maps and images of areas monitored by Webcams on Kïlauea. $A$, Kïlauea forms the southeast portion of the Big Island (Hawai'i). Ongoing eruptions occur at the summit and the east rift zone (ERZ). ERZ lava flows erupted from 1983 to 2007 are in pink, with the currently active flows (July 21, 2007-present) shown in red. B, Shaded relief map of Killauea's summit region, with the current vent in Halema'uma'u Crater shown. HVO is the Hawaiian Volcano Observatory. C, View of Halema'uma'u Crater from HVO, with the degassing plume from the current vent drifting south. The inset view shows a close-up of the vent on November 4, 2008, at which point it was $80 \mathrm{~m}$ wide. $D$, Enlarged map of the ERZ vent area. Meaning of colors as in $A$. E, Photo of a dome fountain formed about $1 \mathrm{~km}$ south of the "Thanksgiving Eve Breakout" (TEB) vent during a period of vigorous breakouts from the tube system in early July 2008. 
The Webcam images are in JPEG red-green-blue (RGB) format, and we need to garner the brightness level from these RGB data. The NTSC (National Television System Committee) approach to convert RGB values to grayscale intensity value (Gonzalez and others, 2004, p. 204) is:

$$
\text { grayvalue }=(0.299 * \mathrm{R})+(0.587 * \mathrm{G})+(0.114 * \mathrm{~B})
$$

RGB images can be converted to grayscale intensity images in this manner in MATLAB using the rgb2gray function in the Image Processing Toolbox, or the equation can simply be entered explicitly without the need for the Image
Processing Toolbox. Although the image data and scripts use grayvalues with 8-bit quantization (0-255), for ease of interpretation we show grayvalues in this paper as percent values, where $0 \%$ is black and $100 \%$ is white.

The following pseudocode conveys, in two forms, the basic principle of the coding approach. The first form is the brute-force approach, which requires a nested loop (that is, rows, then columns) to go through and compare each individual pixel in a given image. This approach is the simplest, but is also time consuming. The second form relies on matrix operations, which is more timeefficient in MATLAB. In practice, we use the second form because of its reduced time, but show the brute-force approach for clarity.

The following pseudocode conveys the basic principle of the coding approach for composite image generation:

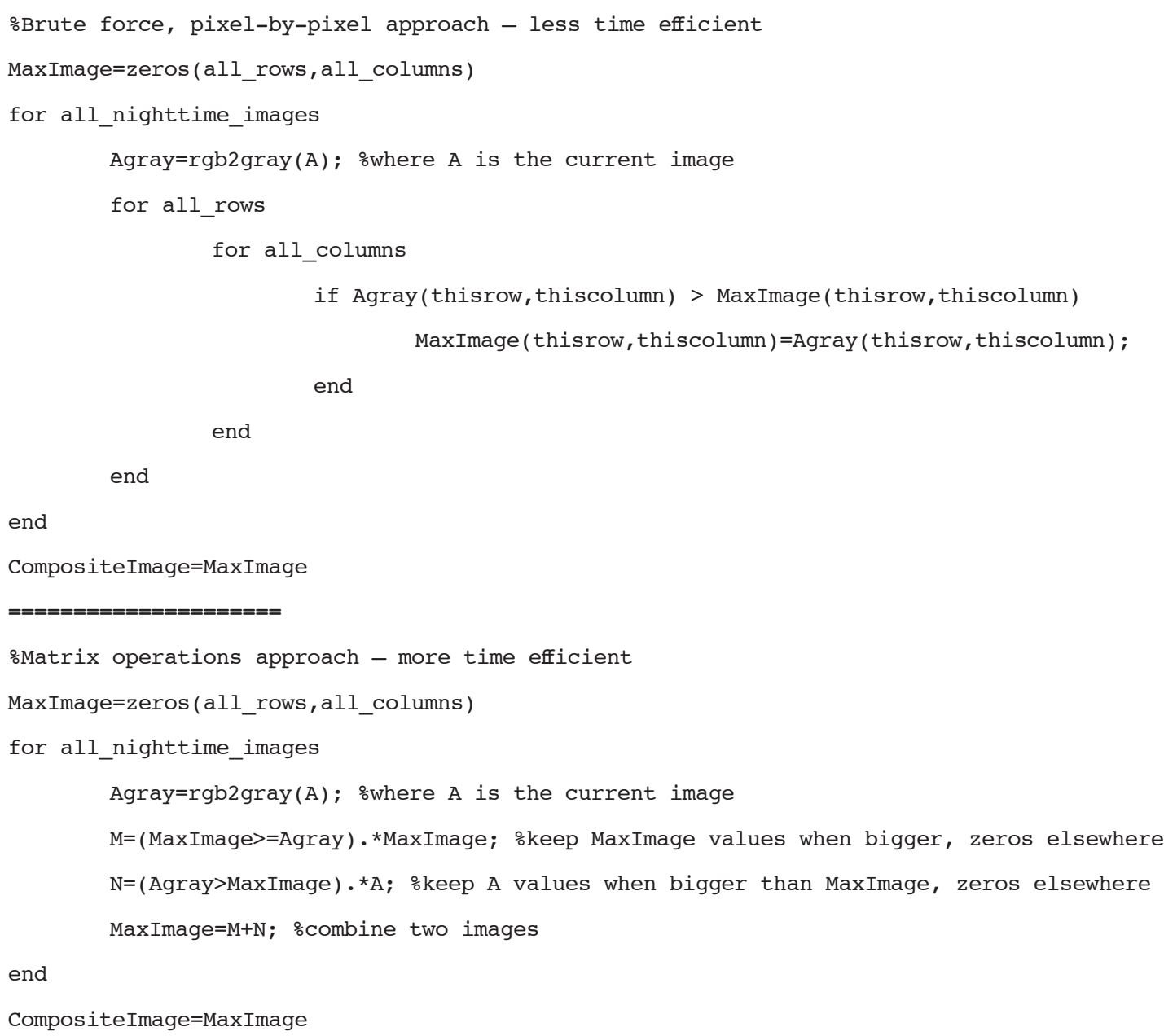

Using a LINUX cron job, MATLAB is automatically started, and the composite image script is run each morning at 5:45 a.m. for all five Webcams (KIcam, K2cam, HMcam, POcam, TEcam) and their respective frames. The script then produces composite images (in JPEG format) for the preceding evening's images. The cron job simply opens a batch file that has the command line call to MATLAB and the appropriate function. For example, the batch file might consist of simply this line: 
matlab -r composite_script

Where -r tells MATLAB to execute the "composite_ script" M-file.

Total processing time for all five cameras (totaling 17 frames) is about 15 minutes on a 64-bit machine with dual 1.8 $\mathrm{GHz}$ processors and $4 \mathrm{~Gb}$ of RAM. The composite images are automatically posted onto the HVO internal data server and accessible over the internal Website as JPEGs.

\section{Results}

The composite images have proven very effective at characterizing activity both at the Halema 'uma'u vent and on the east rift zone of Kîlauea. In an operational sense, they provide a quick screening tool for the preceding night. If anomalous activity is shown by the composite image, one can then examine the individual frames to better characterize and time the activity.

Bad weather can obscure views of the summit vent and flow field by the Webcam, potentially affecting the composite images. However, because the composite images show the brightest values throughout the night, they depict whatever clear views occur, however scant. Thus, the effect of bad weather is minimized. The composite images would only be severely affected if no views whatsoever occur during the night. Because this possibility is hard to rule out, we stress that longer term trends (for example, days to weeks) in the composite images are more reliable than insights from any single night.

At Halema'uma'u, nightly composite images have tracked the frequent changes in vent glow and dimensions throughout the ongoing eruptive activity. Figure 3 shows a selection of composite images taken between the opening of the vent on March 19, 2008, and late June 2009, alongside a time series of vent glow calculated with the approach described in the next section. The March 19, 2008, composite image shows complex glow at the vent due to changes both preceding and related to the vent-opening explosion. The vent at this time was about $35 \mathrm{~m}$ wide. The following day, March 20, the vent brightness was reduced dramatically, possibly a result of collapse material on top of the lava column. Vent glow was commonly bright through April and May 2008, and figure $3 C$ shows the May 10 composite image, when the vent was approximately $50 \mathrm{~m}$ wide. The most intense glow recorded through the ongoing eruption was on August 8, 2008, during a phase of rapid deformation at the summit similar to the deflation-inflation transients
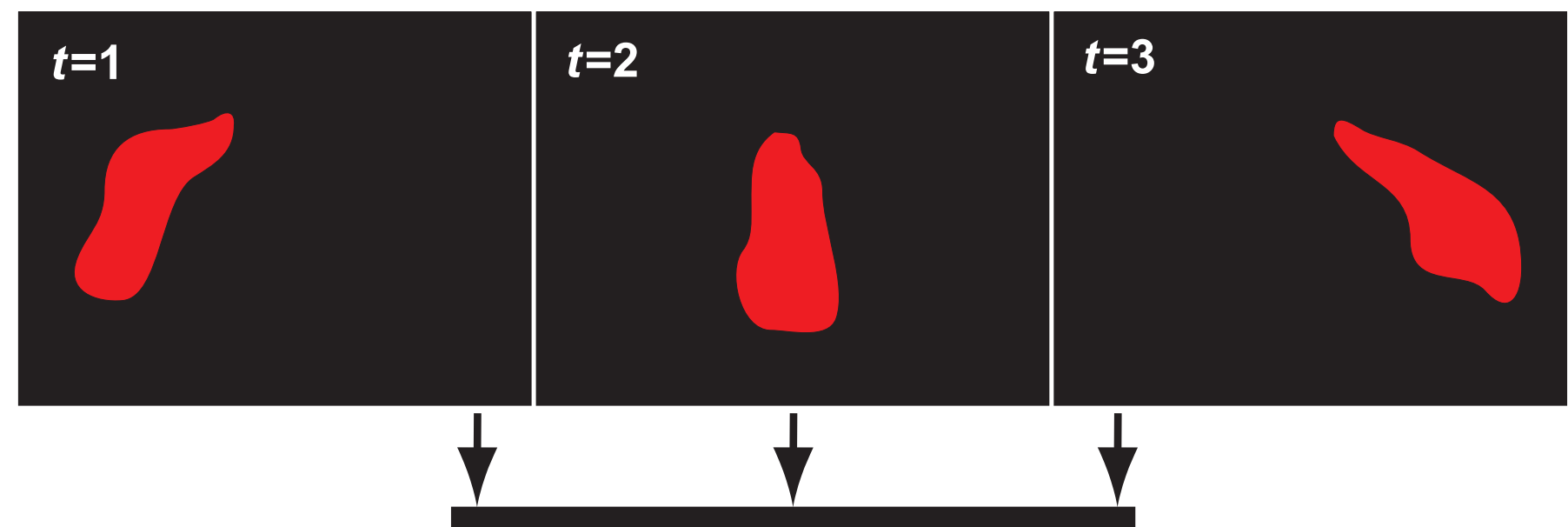
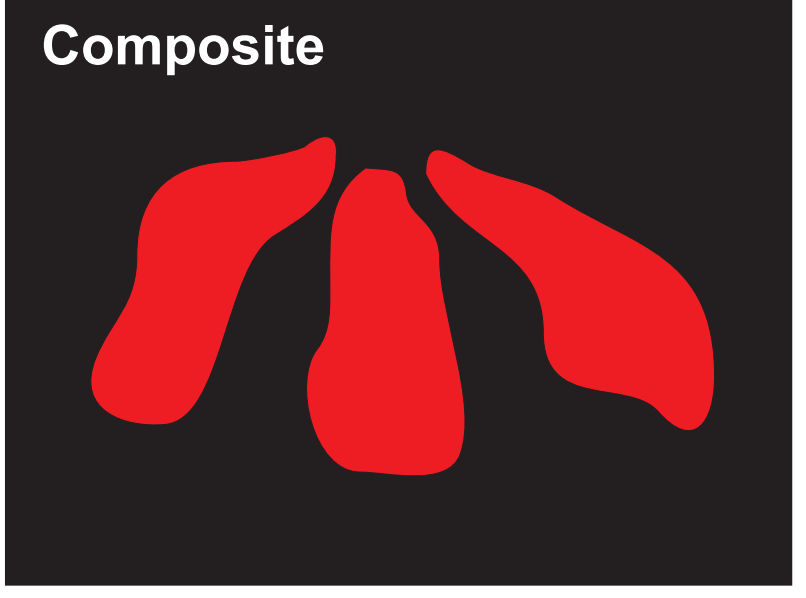

Figure 2. Cartoon showing the principle of composite image generation. By combining images from different times $(\mathrm{t})$, composite images essentially show all incandescence in a field of view over a period of time. 

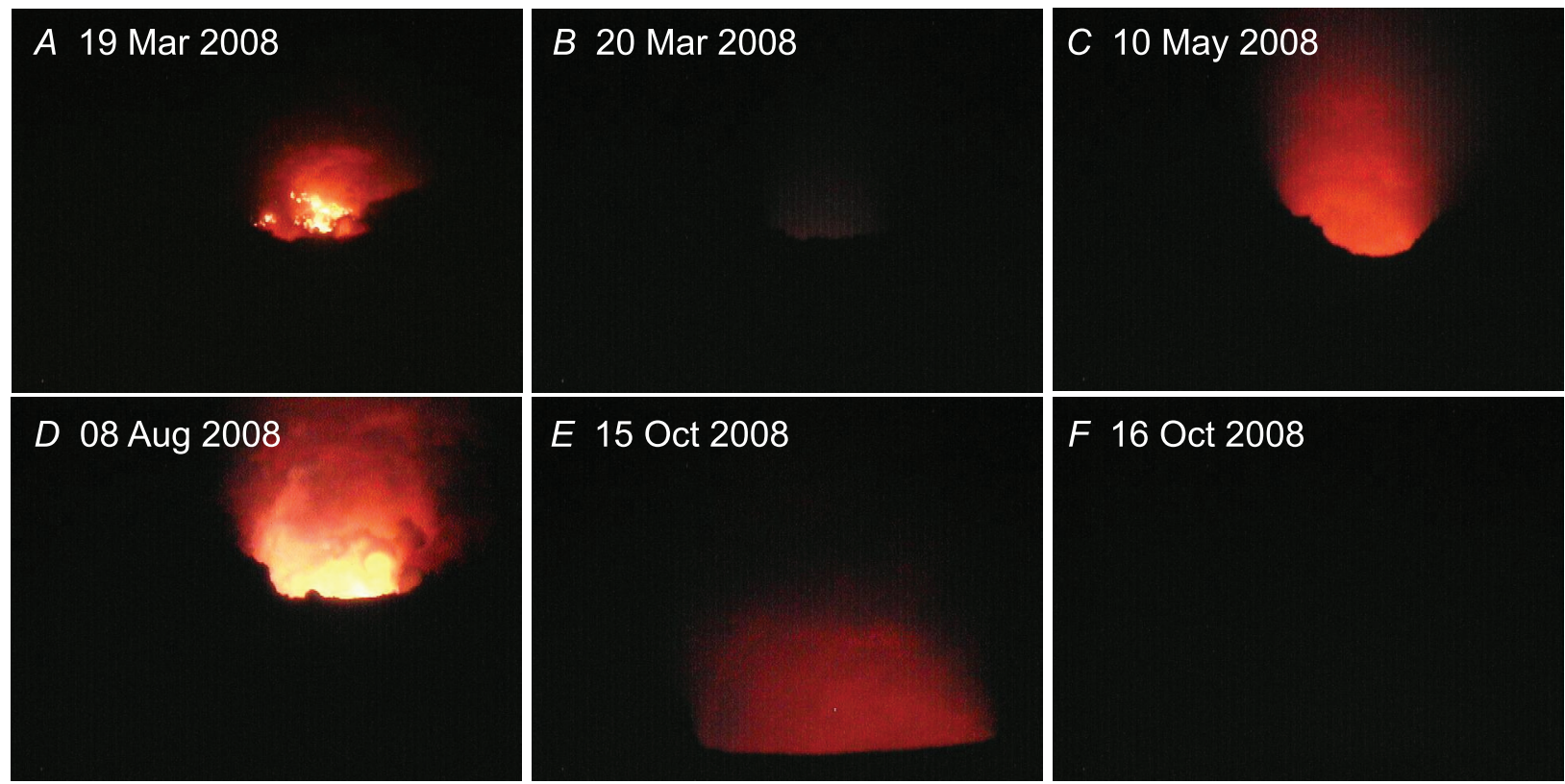

G 07 Jan 2009
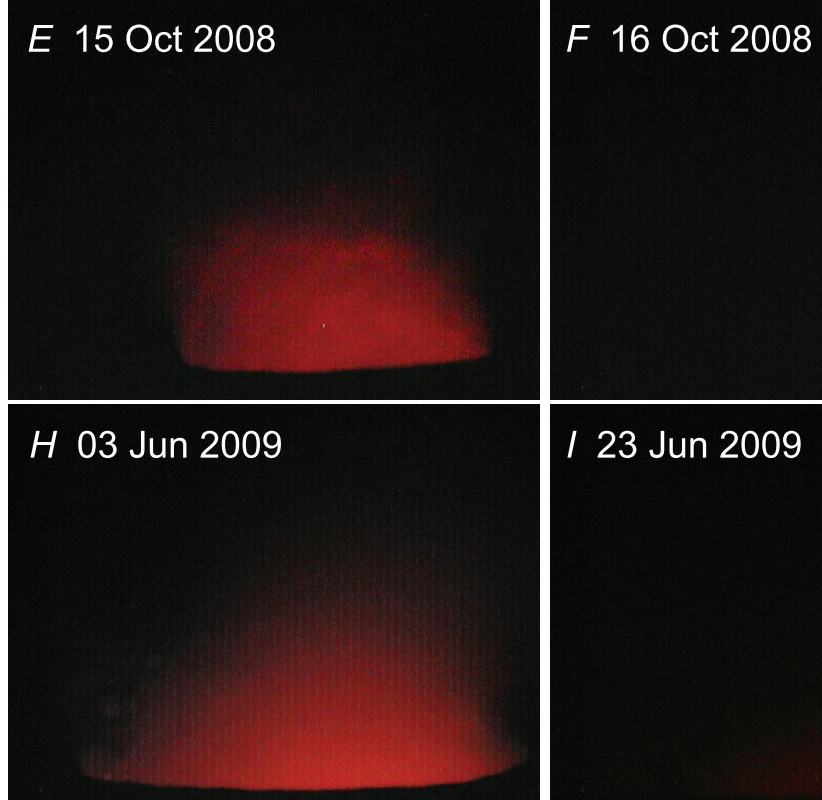

$F-16$ Oct 2008
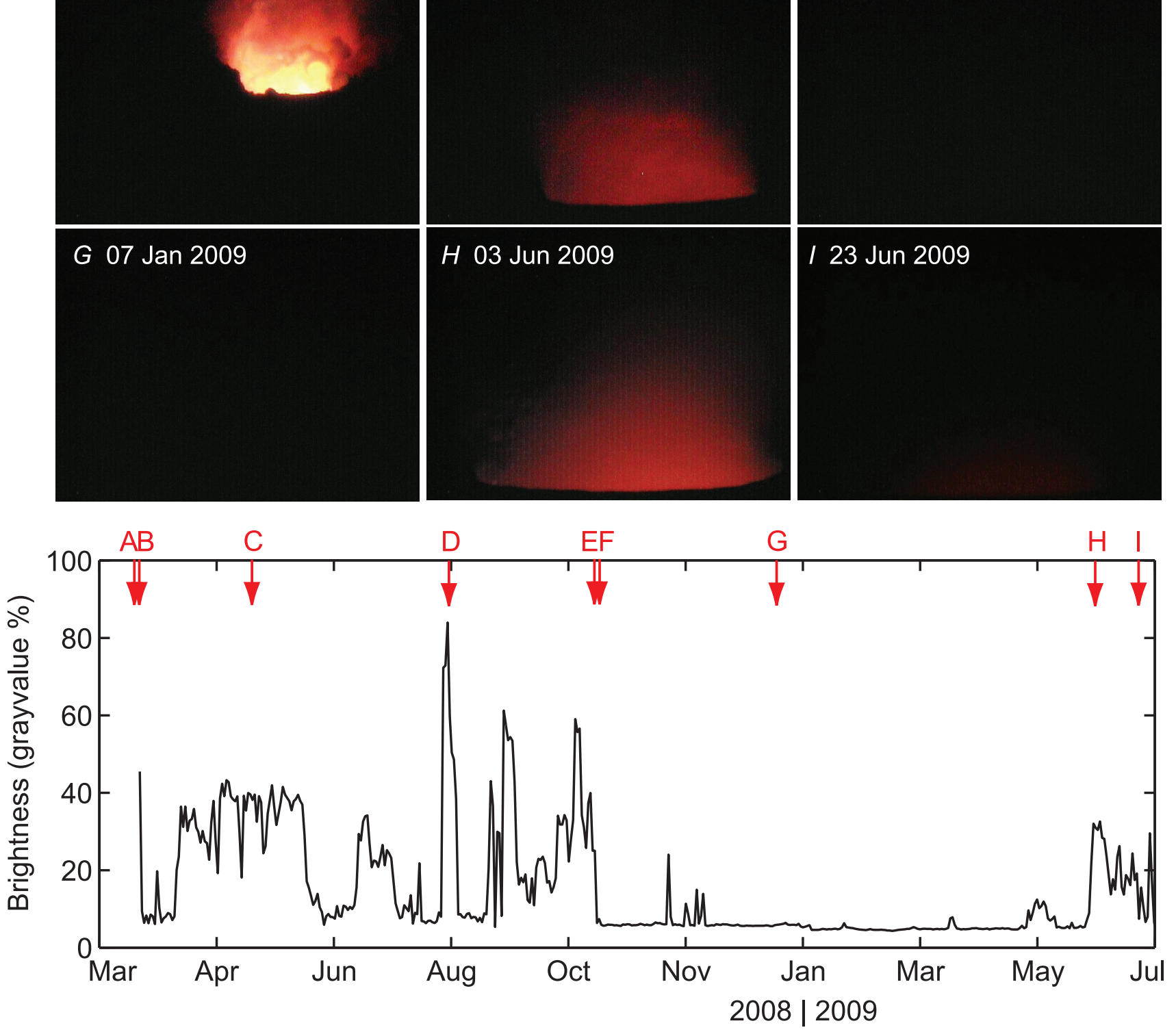

Figure 3. Selected composite images of glow at the Halema'uma'u vent, with graph of daily vent glow values shown below from March 2008 to July 2009. Images show the KIcam Z1 frame. The times of the images are marked on the graph. 
described by Cervelli and Miklius (2003) and Poland and others (2009). Rapid changes in vent glow, like that on March 19-20, 2008, have occurred several times during the eruption; another example is the rapid decrease in glow between October 15 and 16, 2008 (fig. 3E,F). This decrease in glow coincided with a drop in tremor and possible withdrawal of the lava column. The vent was commonly dark between November 2008 and May 2009; an example of the lack of glow is shown for January 7, 2009, in figure $3 G$. Substantial glow returned in June 2009, when the lava surface was visible from the Halema 'uma'u Overlook (fig. $3 H, I$ ). Not surprisingly, the composite images from this time compare well in qualitative terms with visible observations from HVO.

On the east rift zone (fig. 1), the composite images have proven effective at depicting sporadic breakouts from the upper TEB lava tube, where there is a complex of about a dozen small, rootless (that is, tube-fed) lava shields built over the lava tube. One of the largest tube-breakouts of the current episode occurred in early July 2008, when substantial flows emanated from several shields. One shield hosted a small dome fountain that fed an 'a'a flow that traveled several kilometers to the southeast. Figure 4 shows a panorama of three frames (M, R, R1) from the TEB Webcam on July 7, 2008. At the far left, glow from the TEB vent itself is visible as a result of lava rising in the vent. The individual shield breakouts are also clearly visible, including the dome fountain (right side of frame R).

Although developed independently, our composite images share the same principle as the "composite ash images" used at the Alaska Volcano Observatory to summarize ash-cloud activity captured in satellite images over specified intervals (Webley and others, 2009). Composite ash images are calculated using the same pixel-by-pixel approach. However, in the case of ash images, the minimum, not maximum, value is recorded.

\section{Vent Glow Proxy}

\section{Objective and Methodology}

Nighttime glow at the Halema 'uma 'u vent has varied considerably, sometimes correlating with other monitoring parameters. We wanted to create a time-series dataset quantifying the average brightness of glow at the vent for each night.

Although it is possible to create a measurement of average vent glow from each individual nighttime image, we were interested in long-term changes in glow and therefore chose to measure the average vent glow from each night's composite image. The average brightness in each composite image was measured in a window of arbitrary size, equivalent to about $35 \mathrm{~m}$ wide by $18 \mathrm{~m}$ high based on the distance between HVO and the vent. We observed that there was a slight variability in the position of the camera field of view on successive nights so that the location of the vent in the image was not consistent. Therefore, we could not choose a static window location in the image, and instead chose to take a moving window approach-essentially performing a grid search for the location of the brightest window value and assuming that the brightest value location corresponded to an ideal placement of the window over the vent. The results from manual placement (by eye) of the window with this automated approach proved very similar.

The following pseudocode conveys the basic principle of the coding approach for vent glow estimation:

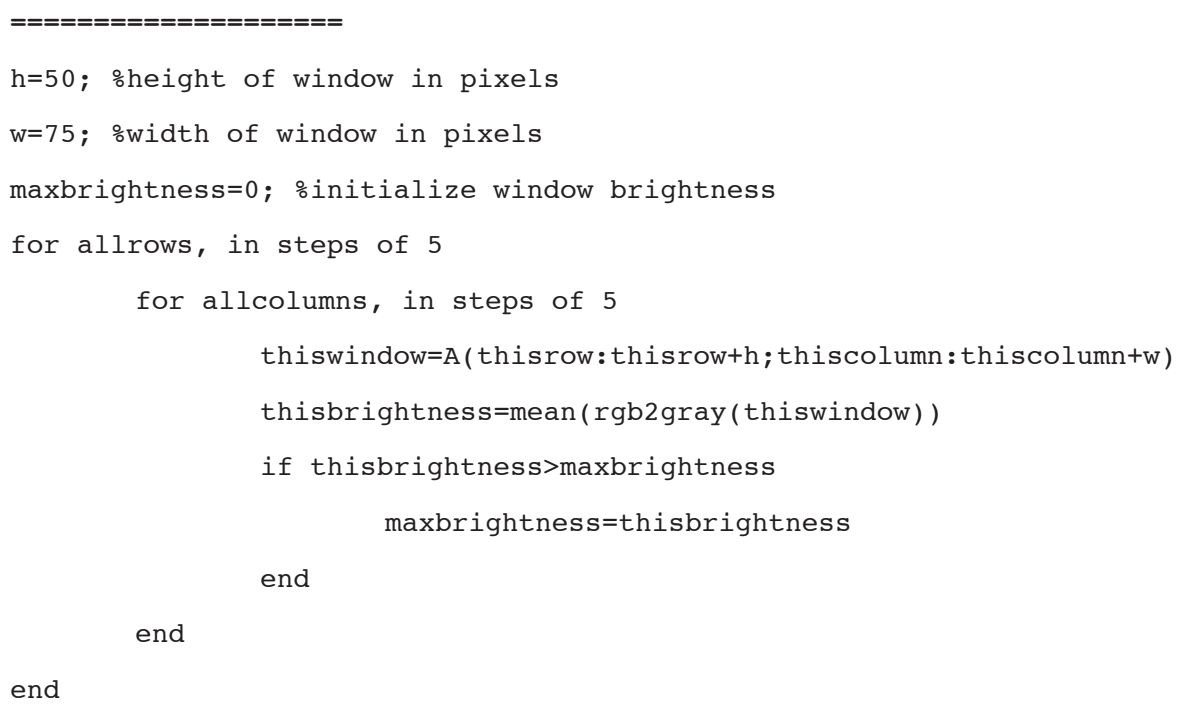


Again, a LINUX cron job automatically starts MATLAB and runs the script each morning, about 15 minutes after the composite image script is run to allow time for composite image generation. The cron job simply opens a batch file that has the command line call to MATLAB and the appropriate function.

matlab -r glow_script

Where "glow_script" is the MATLAB M-file.

Currently, the vent glow measurement is only applied to one camera (KIcam, the camera in the HVO observation tower viewing Halema 'uma' $u$ ) and one of its frames (Z1, which is the zoomed-in view of the vent; see figure 3 ). Total processing time for this single frame is less than 1 minute on a 64-bit machine with dual $1.8 \mathrm{GHz}$ processors and 4 gigabytes of RAM. The script appends the daily glow values to a CSV (comma-separated variable) text file, which is formatted for, and read into, VALVE (Volcano Analysis and Visualization Environment; Cervelli and others, 2002). VALVE is a Webbased plotting program that allows multiple types of real-time monitoring data to be viewed together, facilitating integrated data analysis.

\section{Results}

Figure 3 shows a time series of vent glow from the opening of the vent on March 19, 2008, through June 2009. The graph shows that dramatic short-term changes in glow have occurred frequently. Furthermore, the first 6 months of the eruption consisted of more frequent glow than the second 6 months. This long-term change may be due to a higher lava stand in the vent during the first portion of the eruption, or it may be due to less crusting of the lava surface during this period. The cause of the changes in vent glow during the early portions of the eruption are difficult to establish, because direct observations of the lava surface were first made in September 2008, after considerable widening of the vent, with only sporadic views thereafter. Several short-term increases in vent glow, however, do clearly correspond to changes in behavior and visibility of the lava surface. For instance, clear views of the lava surface were available for a few days at the end of March 2009, when a slight increase in glow was recorded. Likewise, the lava surface was visible in mid-May 2009 and throughout most of June 2009, and both of these periods exhibit significantly increased glow. The March 2009 period of increased lava visibility and glow was preceded by a collapse of a portion of the vent that had masked the open lava surface. Thus, increases in glow and visibility of the lava surface may be due primarily to changes in vent geometry rather than to the height of the lava column. This time series thus shows how the trend in glow is a valuable datastream to compare to visual observations and helps to quantify long- and short-term changes in activity within the vent.

Figure 5 shows several comparisons of vent glow with geophysical datasets collected at HVO. A comparison between summit tilt from the UWE tiltmeter and vent glow for late July and early August 2008 is shown in figure 5A. The tilt data show an overall deflationary trend interrupted by two transient deformation episodes, each consisting of deflation followed by inflation. The first, and smaller, transient produced a minor but significant increase in glow for one night. The second, and larger, transient produced an increase in glow for about one week. Because the lava surface was not directly visible during this phase, we can only speculate on what caused the increase in glow. It may have been changes in lava level due to fluctuations in magma-reservoir pressure or changes in vigor of the lava surface due to changes in degassing rates, which may be related to the deformation transients.

Figure $5 B$ shows changes in summit tremor from seismic station RIM — characterized by real-time seismic amplitude measurement (RSAM; Endo and Murray, 1991) — that corresponded with fluctuations in vent glow in June and July 2009.
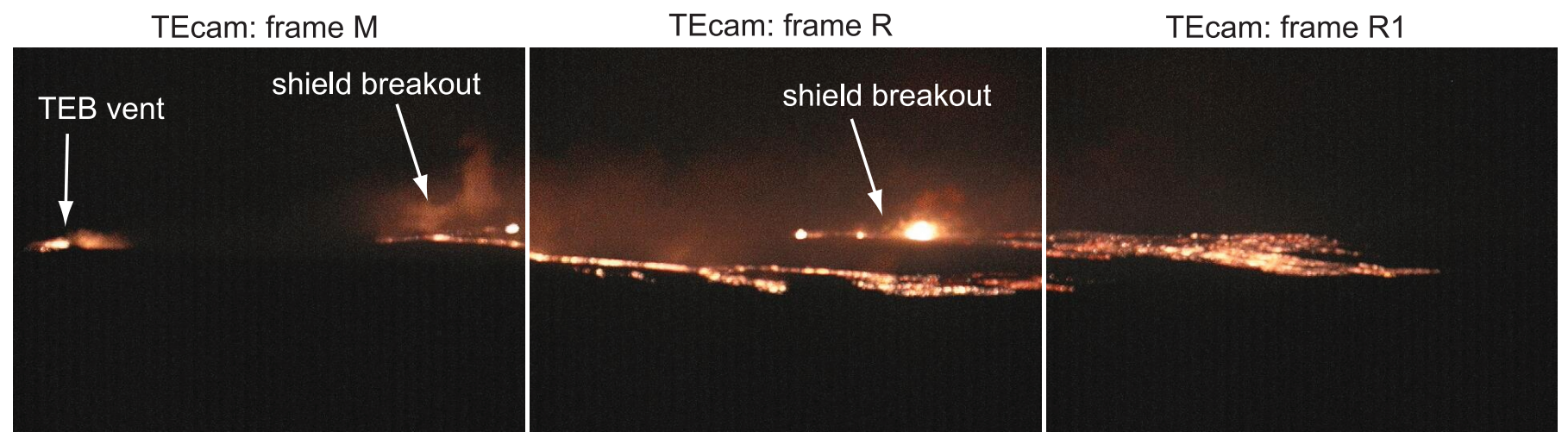

Figure 4. Composite images from July 7, 2008, showing several breakouts from the TEB lava tube. The frames form a panorama covering the TEB shield complex. 

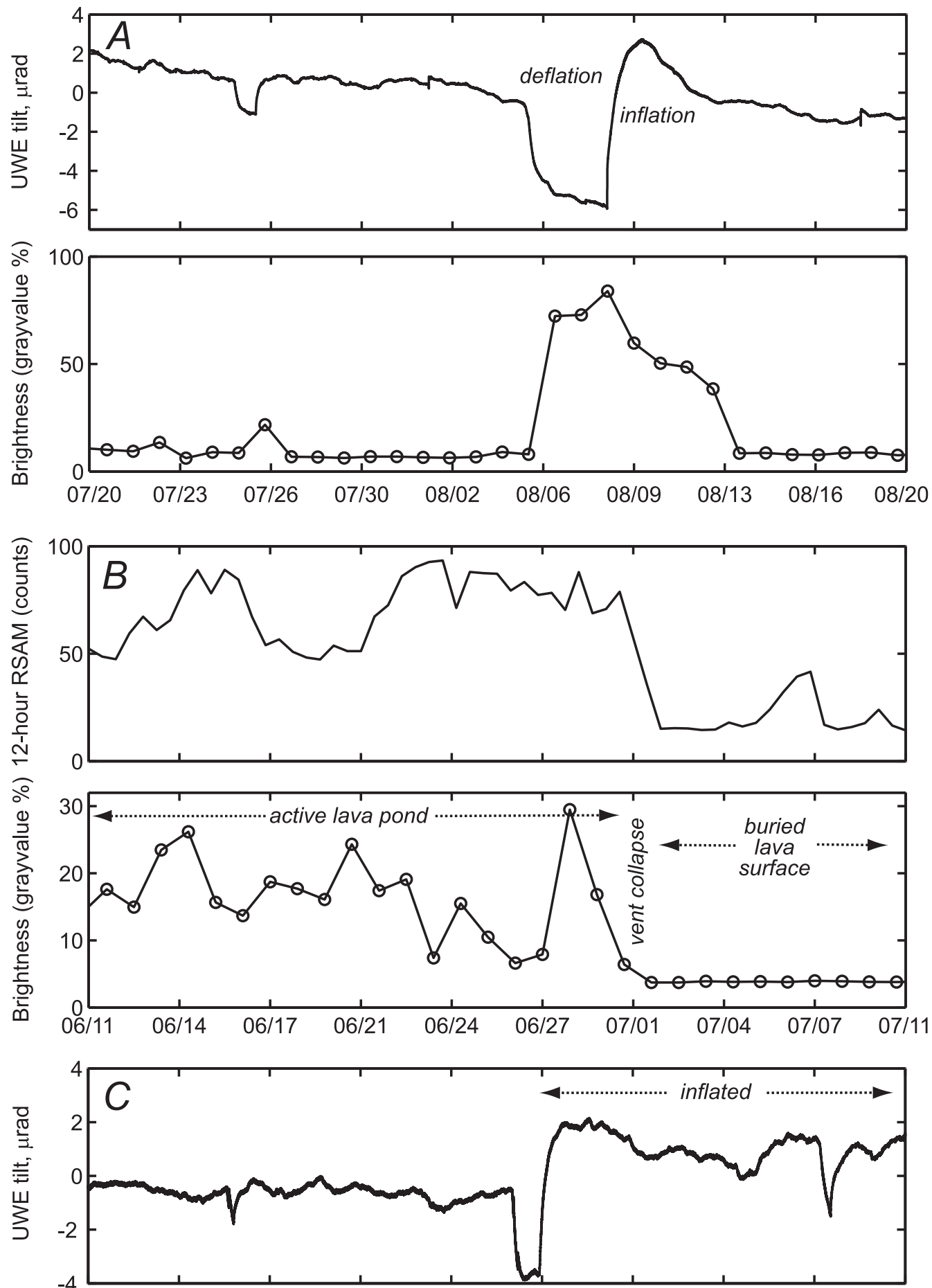

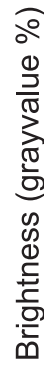

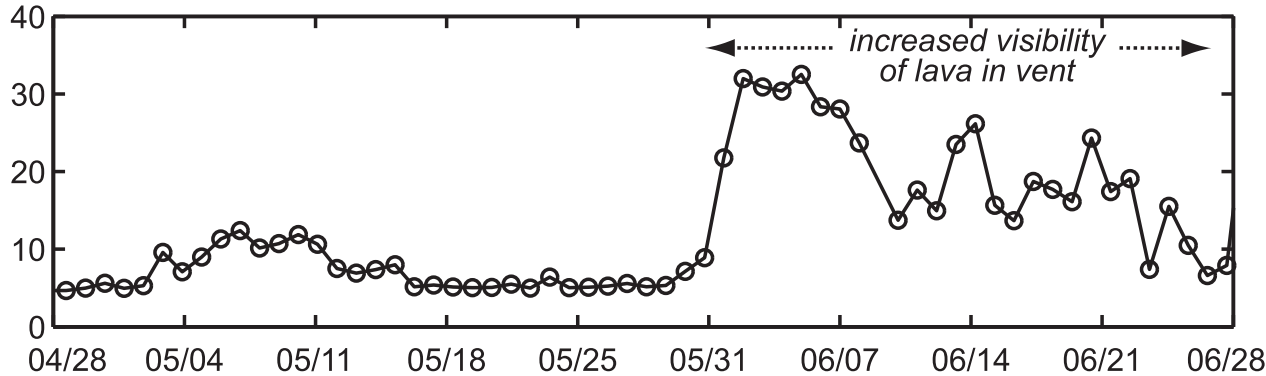

Figure 5. Comparison of vent glow values with other monitoring datasets. $A$, Data from the summit tiltmeter (UWE) for JulyAugust 2008 showing two deflation-inflation cycles. Halema'uma'u vent glow increased during both deformation cycles, indicating changes in the behavior of the lava column. $B$, Summit realtime seismic amplitude measurements (RSAM) compared to Halema'uma'u vent glow for June-July, 2009, again indicating that vent glow can be used to track changes in the state of the lava surface. C, Summit tilt (UWE) compared to vent glow for April-June 2009, showing that vent glow (and lava activity in the vent) increased during an inflated period at the summit.

Date in 2008 (for $A$ ) or $2009(B, C)$ 
RSAM levels were elevated during much of June 2009 and were associated with the appearance of an active lava pond about $200 \mathrm{~m}$ below the Halema 'uma' $\mathrm{u}$ vent rim. The exposed and active lava surface was also responsible for elevated glow throughout most of June. On June 30, a series of vent collapses buried the lava pond in rubble. RSAM dropped abruptly after the collapse events, perhaps because the rubble cover affected the nature of lava circulation and degassing in the uppermost lava column. The burial of the lava surface was shown by the cessation of glow, after which glow values were $<5$ percent. In this case, images with no visually-detectable glow had brightness values $>0$ percent (but typically $<5$ percent) due to image noise. The level of image noise, and resulting "baseline" brightness value, is likely dependent upon the camera model. This example shows how the vent glow values can help interpret processes influencing other datasets, such as seismicity.

Figure $5 C$ shows a comparison of summit tilt (from UWE tiltmeter) with vent glow for April-June 2009.

Pronounced inflation began on June 1 and coincided with the appearance of the lava surface deep within the Halema 'uma ' $u$ vent (possibly resulting from a collapse of the floor of the vent cavity). With the appearance of the lava surface, glow increased dramatically. By the end of June, vent glow showed a gradual decrease, which coincided with observations of increased crusting of the lava surface.

As noted above, bad weather may affect the composite image values and resulting vent glow values, although the composite image approach-by depicting the brightest value throughout each night — minimizes this as much as possible. Nevertheless, because of the potential effects of weather, we stress that long-term trends are more reliable than any individual data points. Figure 3 shows sustained brightness values for weeks - even in the presence of variable weather at the summit - and clear systematic changes that suggest that the effects of weather are not overwhelming there. Figure 5, by showing clear geophysical correlations with vent glow in the midst of variable weather, reinforces this inference. Overall, it appears that the effects of weather at Kilauea are not prohibitive of deriving useful information from monitoring of volcanic incandescence.

\section{Conclusions}

We have presented two simple, but effective, MATLAB tools for improving monitoring of volcanic incandescence in Webcam images. The first tool, composite image generation, provides an efficient means of summarizing a time period's activity in one image. The second tool, the vent glow proxy, permits quantification of vent brightness through time. The results from these tools have been used on a daily basis at HVO for tracking activity at the east rift zone eruption and at the new vent in Halema'uma 'u Crater at Kîlauea's summit. We have also shown how the vent glow time series is a useful tool for analyzing volcanic activity, along with other monitoring datasets such as deformation and seismicity.
There is much potential for additional automated analyses of volcanic activity in Webcam images at HVO. The next priority is an incandescence alarm, similar to the idea presented by Lovick and others (2008), which would provide an early warning (for example, via email or text message) of incandescence and would be a valuable supplement to existing alarms for seismicity and deformation during off-work hours. Building on this for regions where lava flows could occur, one could (theoretically) produce a rough map of the detected areas of incandescence (and, thus, active lava), by considering the local topography and viewing geometry of the cameras. From a continuously updated map of incandescent areas, it would be simple to produce automated estimates of flow advance rates.

\section{Acknowledgements}

We thank Hawaiian Volcano Observatory staff, particularly Asta Miklius and Tim Orr, for technical assistance in implementing these scripts and maintaining the Webcams. Reviews by R. Hoblitt, T. Orr, T.J. Takahashi, and W. Scott are greatly appreciated.

\section{References}

Behncke, B., Falsaperla, S., and Pecora, E., 2009, Complex magma dynamics at Mount Etna revealed by seismic, thermal, and volcanological data: Journal of Geophysical Research, v. 114, B03211, doi:10.1029/2008JB005882.

Cervelli, P.F., and Miklius, A., 2003, The shallow magmatic system of Kilauea Volcano, in Heliker, C., Swanson, D.A., and Takahashi, T.J., eds, The Pu'u 'O'o-Kupaianaha eruption of Kilauea Volcano, Hawai ' $i$ - the first 20 years: U.S. Geological Survey Professional Paper 1676, p. 149-163.

Cervelli, D.P., Cervelli, P.F., Miklius, A., Krug, R., and Lisowski, M., 2002, VALVE; volcano analysis and visualization environment [abs.]: Eos (American Geophysical Union Transactions), v. 83, no. 47, Fall meeting supplement, abs. U52A-01, p. F3.

De Angelis, S., and McNutt, S.R., 2007, Observations of volcanic tremor during the January-February 2005 eruption of Mt. Veniaminof, Alaska: Bulletin of Volcanology, v. 69, no. 8, p. 927-940.

Deroin, N., McNutt, S.R., and Williams, E., 2005, Seismic, webcam and satellite observations of eruptions at Veniaminof Volcano, Alaska, January-February [abs.]: Eos (American Geophysical Union Transactions), v. 86, no. 52, Fall meeting supplement, abs. V21C-0615.

Endo, E.T., and Murray, T., 1991, Real-time seismic amplitude measurement (RSAM); a volcano monitoring and prediction tool: Bulletin of Volcanology, v. 53, no. 7, p. 533-545. 
Gonzalez, R.C., Woods, R.E., and Eddins, S.L., 2004, Digital image processing using MATLAB $®$ : Upper Saddle River, New Jersey, Pearson-Prentice Hall.

Heliker, C., and Mattox, T.N., 2003, The first two decades of the Pu'u 'O'o-Kupaianaha eruption; chronology and selected bibliography, in Heliker, C., Swanson, D.A., and Takahashi, T.J.,eds., The Pu'u 'O'o-Kupaianaha eruption of Kilauea Volcano, Hawai ' $\mathrm{i}$ - the first 20 years: U.S. Geological Survey Professional Paper 1676, p. 1-27.

Hoblitt, R.P., Orr, T.R., Castella, F., and Cervelli, P.F., 2008, Remote-controlled pan, tilt, zoom cameras at Kilauea and Mauna Loa volcanoes, Hawai ${ }^{i}$ : U.S. Geological Survey Scientific Investigations Report 2008-5129, 14 p.

Kirianov, V.Y., Neal, C.A., Gordeev, E.I., and Miller, T.P., 2002, The Kamchatkan Volcanic Eruption Response Team (KVERT): U.S. Geological Survey Fact Sheet 064-02 [in English] and 151-02 [in Russian], 2 p. (Also available at http://pubs.usgs.gov/fs/2002/fs064-02/.)

Lovick, J., Lawlor, O., Dean, K., and Dehn, J., 2008, Observation of volcanoes through webcams; tools and techniques [abs.]: Eos (American Geophysical Union Transactions), v. 89, no. 53, Fall meeting supplement, abs. V51A-2019.

Orr, T.R., Patrick, M.R., Wooten, K.M., Swanson, D.A., Elias, T., Sutton, A.J., Wilson, D.C., and Poland, M.P., 2008, Explosions, tephra, and lava; a chronology of the 2008 summit eruption of Kilauea Volcano, Hawai' $i$ [abs.]: Eos (American Geophysical Union Transactions), v. 89, no. 53, Fall meeting supplement, abs. V11B-2018.

Poland, M.P., Dzurisin, D., LaHusen, R.G., Major, J.J., Lapcewich, D., Endo, E.T., Gooding, D.J., Schilling, S.P., Janda, C.G., 2008a, Remote camera observations of lava dome growth at Mount St. Helens, Washington, October 2004 to February 2006, in Sherrod, D.R., Scott, W.E., Stauffer, P.H., eds., A volcano rekindled: the renewed eruption of Mount St. Helens, 2004-2006: U.S. Geological Survey Professional Paper 1750, p. 225-236.
Poland, M.P., Miklius, A., Orr, T.R., Sutton, A.J., Thornber, C.R., and Wilson, D.C., 2008b, New episodes of volcanism at Kilauea Volcano, Hawai 'i: Eos (American Geophysical Union Transactions), v. 89, no. 5, p. 37-48.

Poland, M., Huth, T.E., and Miklius, A., 2009, Source processes of short-term, transient tilt events at Kilauea Volcano, Hawaii, [abs.]: Eos (American Geophysical Union Transactions), v. 90, no. 52, Fall meeting supplement, abs. V43G-2331.

Snedigar, S.F., Cameron, C.E., and Nye, C.J., 2006, The Alaska Volcano Observatory Website-a tool for information management and dissemination [abs.]: Eos (American Geophysical Union Transactions), v. 87, no. 52, Fall meeting supplement, abs. V51C-1695.

Swanson, D., Wooten, K., and Orr, T., 2009, Buckets of ash track tephra flux from Halema uma 'u Crater, Hawai i: Eos (American Geophysical Union Transactions), v. 90, no. 46 , p. 427.

Tupper, A., Kinoshita, K., Kanagaki, C., Iino, N., and Kamada, Y., 2003, Observations of volcanic cloud heights and ash-atmosphere interactions [abs.], in WMO/ICAO Third International Workshop on Volcanic Ash, Toulouse, France, Sept. 29-Oct. 3, 2003 [Abstract volume]: Toulouse, France, Meteo-France World Meteorological Organization (WMO) and International Civil Aeronautical Organization (ICAO).

Webley, P.W., Dehn, J., Lovick, J., Dean, K.G., Bailey, J.E., and Valcic, L., 2009, Near-real-time volcanic ash cloud detection;experiences from the Alaska Volcano Observatory: Journal of Volcanology and Geothermal Research, v. 186, no. 1-2, p. 79-90.

Wilson, D.C., Elias, T., Orr, T.R., Patrick, M.R., Sutton, A.J., and Swanson, D.A., 2008, Small explosion from new vent at Kilauea's summit: Eos (American Geophysical Union Transactions), v. 89, no. 22, p. 203. 


\section{Appendix 1. MATLAB Code for Composite Image Generation}

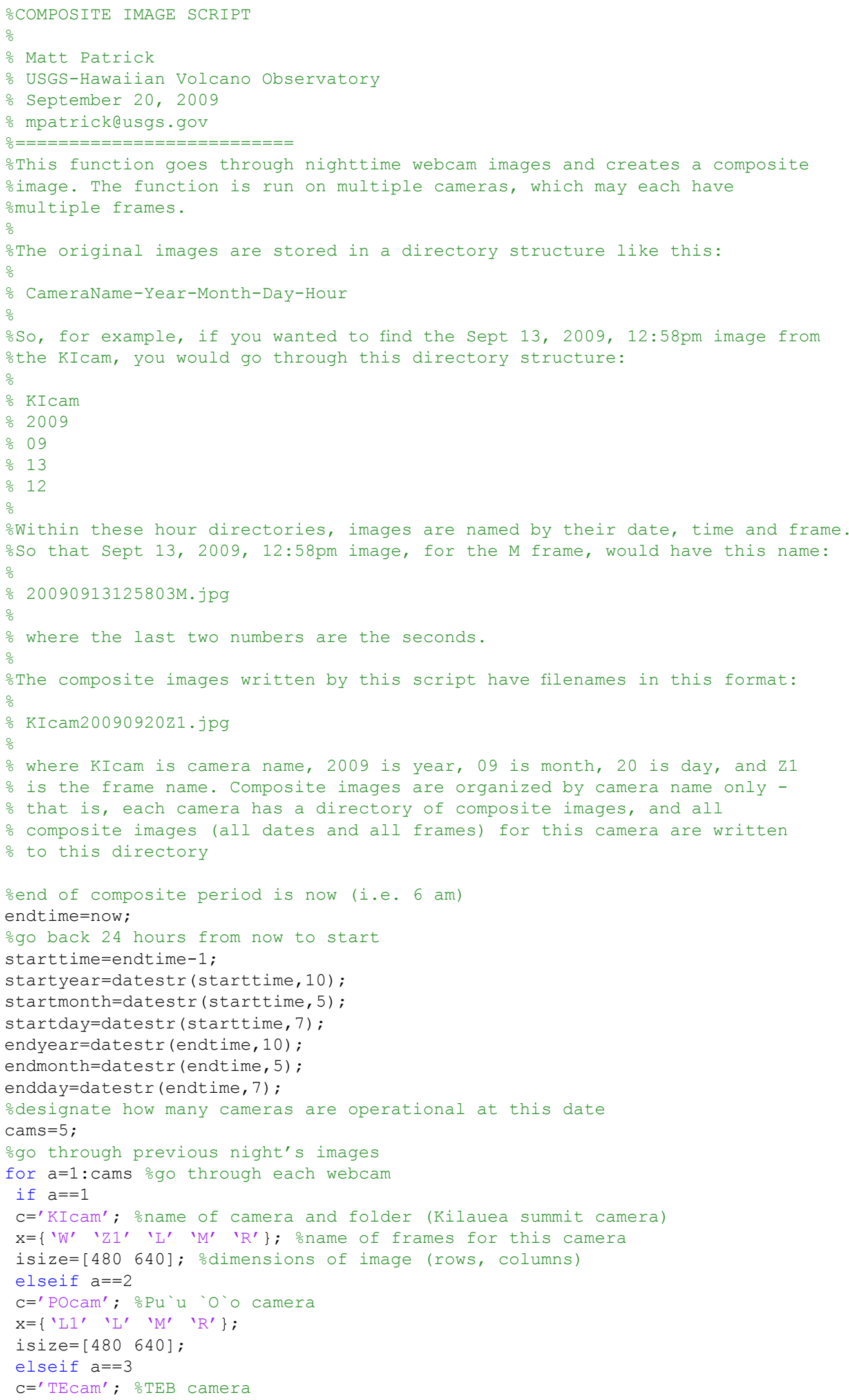




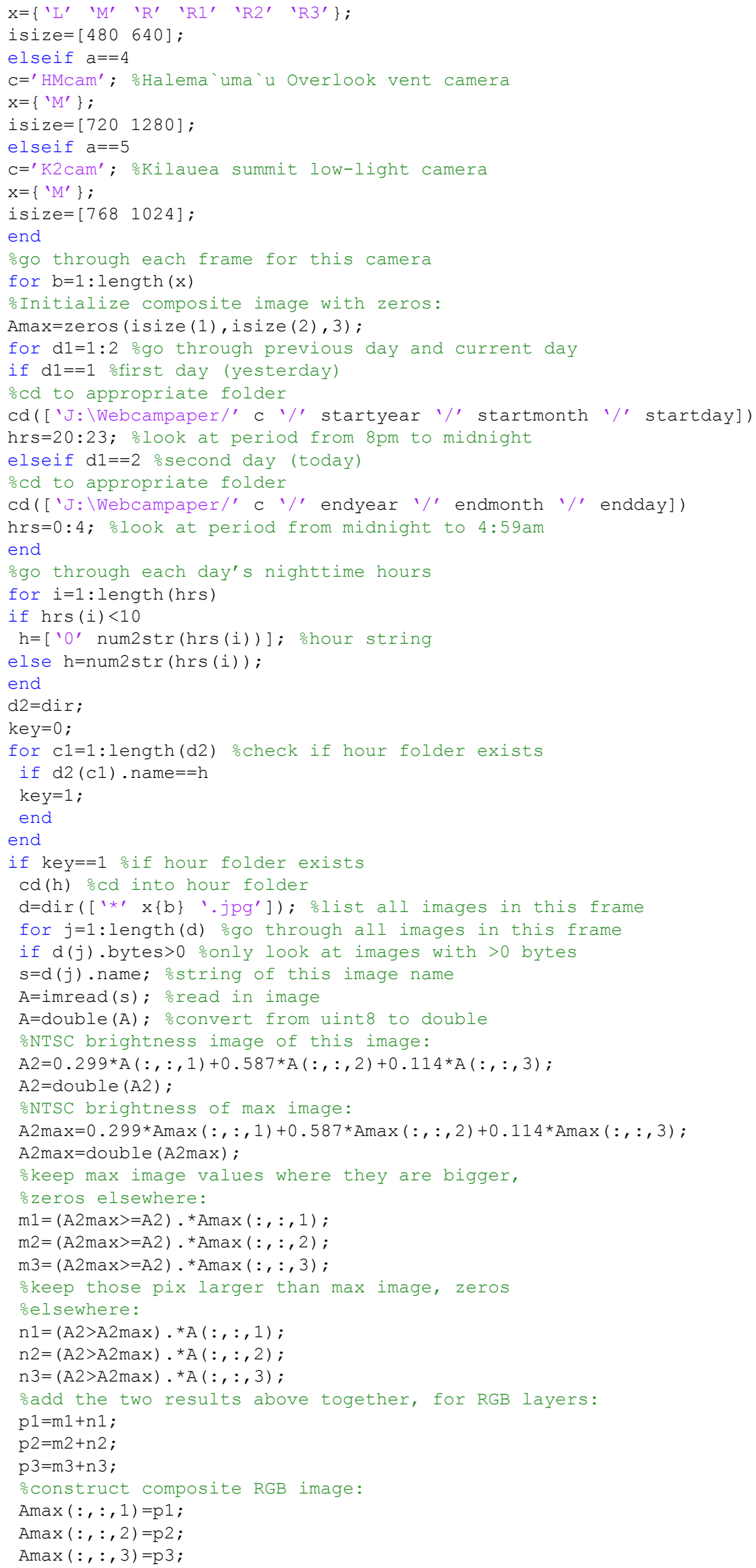


end

end ond of each image

$\mathrm{cd}$. .

end $\%$ end of if-statement checking to see if hour folder exists

end \%end of each hour

end $\frac{\circ}{\circ}$ end of each day

Amax=uint8 (Amax); oconvert double image to uint8

cd('J:\Webcampaper \composites'); \%cd to directory to put composite images

$\mathrm{s}=\left[\mathrm{c}\right.$ endyear endmonth endday $\left.\mathrm{x}\{\mathrm{b}\} \cdot \cdot j \mathrm{pg} \mathbf{\prime}^{\prime}\right]$; ostring of composite image name

imwrite (Amax,s,'jpeg'); owrite composite image

end \%end of each frame loop

end \%end each webcam loop

\section{Appendix 2. MATLAB Code for Vent Glow Measurement}

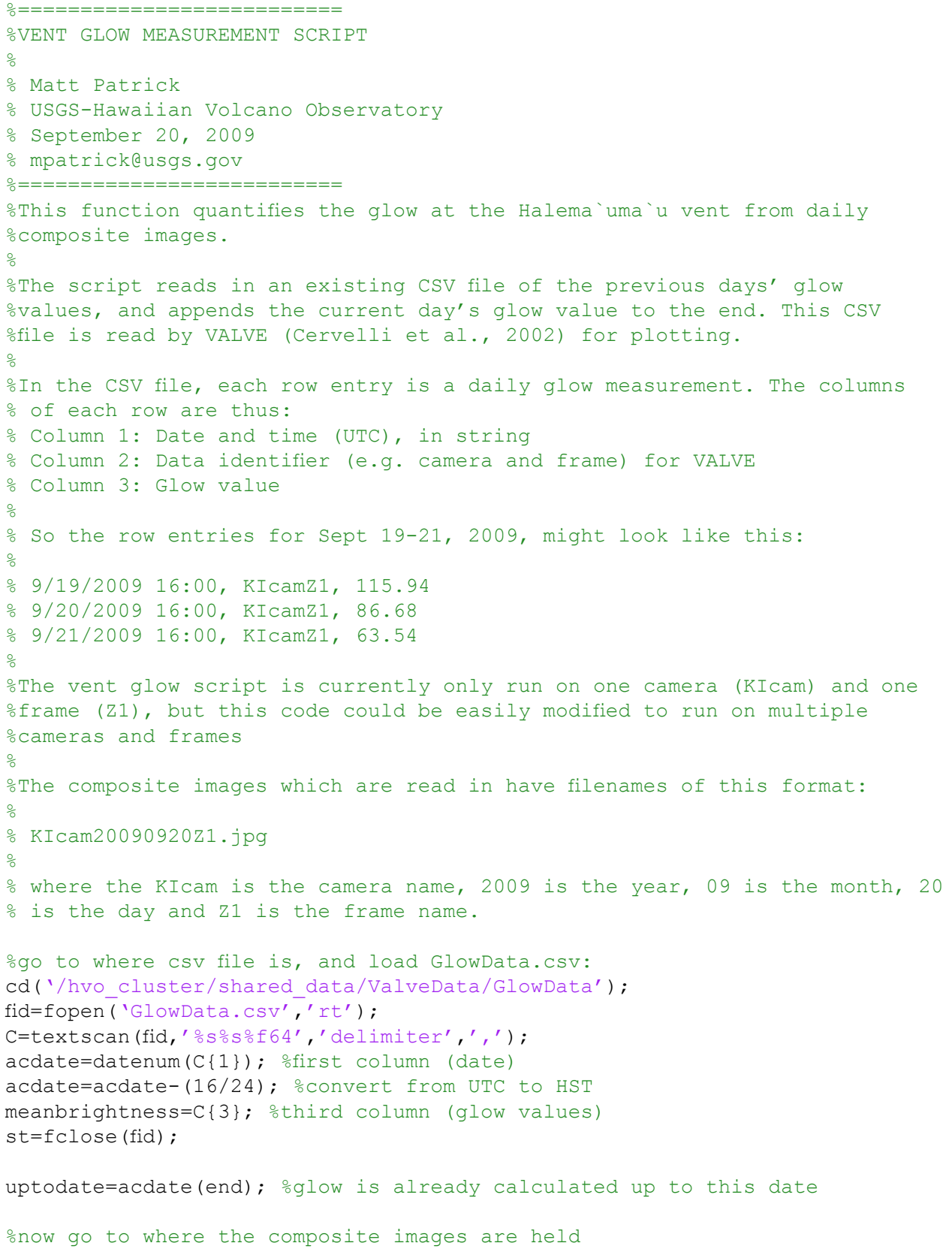




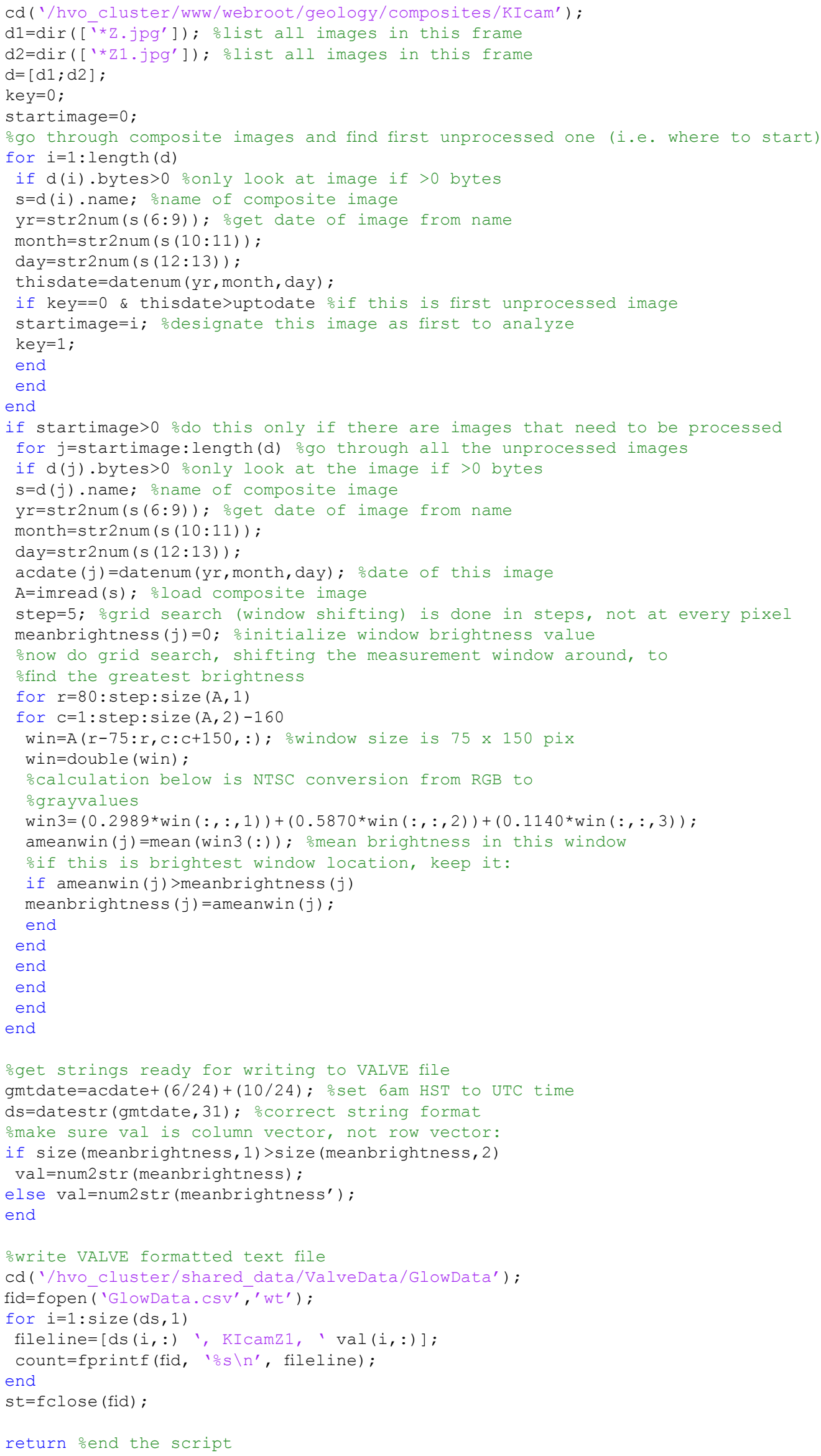




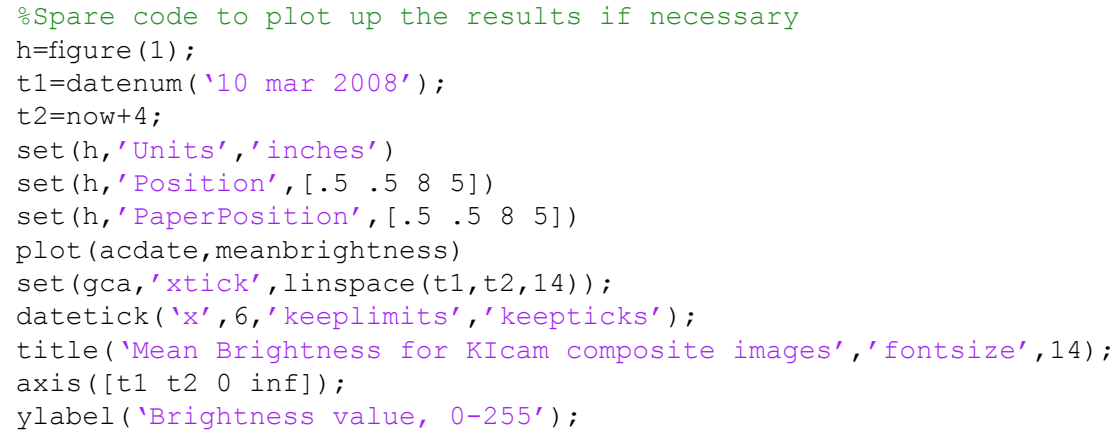


This page left intentionally blank. 


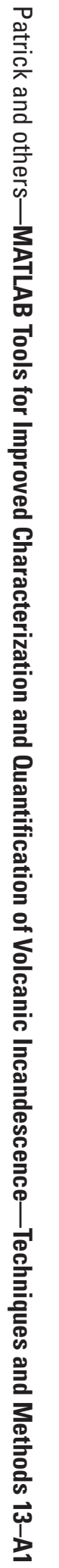

